Disponível em:

http://editora.unoesc.edu.br/index.php/race

RACE, Joaçaba, v. 16, n. 1, p. 147-174, jan./abr. 2017

\title{
O CONHECIMENTO PRODUZIDO PELOS PROGRAMAS DE PÓS-GRADUAÇÃO EM ADMINISTRAÇÃO NAS UNIVERSIDADES PERNAMBUCANAS: ANÁLISE DA PRODUÇÃO ACADÊMICA À LUZ DO PROFISSIONALISMO DE ELIOT FREIDSON
}

The knowledge produced by business Administration postgraduate programs in universities from the State of Pernambuco: analysis of academic production in the light of Eliot Freidson's professionalism

Fabiana Ferreira Silva

E-mail: professorafabyana@gmail.com

Mestre em Administração pela Universidade Federal de Pernambuco; Doutoranda em Educação na Universidade Federal de Pernambuco; Professora do Departamento de Administração da Universidade Federal Rural de Pernambuco. Endereço para contato: Rua Dom Manoel de Medeiros, Portão Z3, Prédio Professor Ariano Suassuna, $2^{\circ}$ andar, sala 4, Dois Irmãos, 52171-900, Recife, Pernambuco, Brasil.

Artigo recebido em 29 de junho de 2016. Aceito em 08 de agosto de 2016. 


\section{Resumo}

Neste trabalho teve-se como objetivo analisar o conhecimento produzido pelos programas de pós-graduação stricto sensu em Administração de instituições pernambucanas. Recorreu-se às contribuições de Eliot Freidson (1986, 1996, 1998, 2001) como lente teórica para nortear a pesquisa, uma vez que, para esse autor, o acesso exclusivo ao mercado de trabalho e o reconhecimento de determinada profissão podem ser conseguidos por meio da combinação entre conhecimento formal e credenciamento. Trata-se de uma pesquisa de natureza qualitativa, cujos dados foram obtidos mediante pesquisa bibliográfica e documental, sendo tratados por meio da análise de conteúdo temática proposta por Bardin (2009). Constatou-se que a produção acadêmica dos programas de pós-graduação analisados contempla estudos sobre o conhecimento construído e socializado na graduação em Administração nos cursos presencial e a distância. Entretanto, não foram identificadas pesquisas sobre a atuação dos Conselhos Estadual e Federal em Administração, bem como sobre a intervenção do Estado na profissão. Os dados coletados e os fatores essenciais ao profissionalismo apresentados por Freidson evidenciaram que o conhecimento especializado adquirido nas instituições de ensino pode constituir elemento de inclusão ou exclusão, mas também de hierarquização e diferenciação profissional na atuação dos administradores.

Palavras-chave: Sociologia das profissões. Contribuições de Eliot Freidson. Produção acadêmica sobre Administração.

\section{Abstract}

This study aimed to analyze the knowledge produced by business Administration postgraduate programs of institutions from the State of Pernambuco. It was based on the contributions of Eliot Freidson (1986, 1996, 1998, 2001) as a theoretical lens to guide the research, since, for this author, the exclusive access to the labor market and the recognition of a particular profession can be achieved through a combination of formal knowledge and accreditation. It consists of a qualitative study, whose data was obtained by bibliographic and documentary research, being treated by the thematic content analysis proposed by Bardin (2009). It was found that the academic production of the analyzed postgraduate programs contemplates studies on the knowledge built and socialized in classroom and distance courses in business Administration. However, no research involving the performance of State and Federal Councils in Business Administration were identified, as well as the State intervention in the profession. The data collected and the factors essential to professionalism presented by Freidson evidenced that the specialized knowledge acquired in educational institutions can constitute an element of inclusion or exclusion, but also of hierarchization and professional differentiation in the actions of the Administrators.

Keywords: Sociology of professions. Contributions of Eliot Freidson. Academic production on business Administration. 


\section{INTRODUÇÃO}

O debate sobre o que configura uma profissão no campo sociológico envolve diferentes posições teóricas. Contudo, possuir uma base de conhecimentos constitui um elemento característico requerido para o exercício profissional conforme diferentes perspectivas da sociologia das profissões.

Sem a pretensão de aprofundar os aspectos que permeiam as discussões teóricas sobre a sociologia das profissões, optou-se por situar o debate identificando como o conhecimento, proveniente de um processo de aprendizagem de longa duração, surge como um fator diretamente relacionado ao desenvolvimento de atividades profissionais. Para tanto, considera-se que “[...] a formação constitui um elemento importante do processo de profissionalismo, sendo o estabelecimento de uma agência formadora e a fundação de uma associação profissional concebidos como estágios do desenvolvimento das profissões.” (WEBER, 2003, p. 1128).

Neste trabalho tem-se como foco de análise a formação em Administração, especificamente, os conhecimentos construídos e socializados nas instituições de ensino. A profissão de Administrador foi regulamentada no Brasil por meio da Lei n. 4.769, de 09 de setembro de 1965, cujo objetivo era restringir o acesso ao mercado profissional apenas aos portadores de títulos universitários (CONSELHO FEDERAL DE ADMINISTRAÇÃO, 2015a). Trata-se de uma das áreas com o maior número de matrículas no ensino superior, ocupando o primeiro lugar no ranking dos cursos mais procurados, conforme o Censo da Educação Superior de 2013, bem como o segundo curso com mais matrículas no Censo realizado em 2014 (INSTITUTO NACIONAL DE ESTUDOS E PESQUISA EDUCACIONAIS ANÍSIO TEIXEIRA, 2013, 2014). No que se refere aos cursos de pós-graduação, de acordo com dados da Coordenação de Aperfeiçoamento de Pessoal de Nível Superior (Capes), em 2015 o Brasil possuía 5.812 cursos de mestrado e doutorado, dos quais 210 eram da área de Administração, representando a sexta área com mais cursos de pós-graduação stricto sensu no País (COORDENAÇÃO DE APERFEIÇOAMENTO DE PESSOAL DE NÍVEL SUPERIOR, 2015).

Nesse cenário, enquanto há um empenho por parte do Governo e das instituições educacionais em elevar o número de mestres e doutores, Cunha (2009, p. 82) chama a atenção “[...] para a responsabilidade das políticas públicas e das instituições na proposição mais sistemática de investimentos na formação profissional.” Já Pimenta (2002) destaca que o crescimento quantitativo dos sistemas de ensino não tem produzido um resultado formativo (qualitativo) adequado às exigências da população 
envolvida, nem às exigências das demandas sociais. Essas autoras têm uma preocupação especial com a formação de professores, porém tais estudos apontam reflexões sobre o desenvolvimento da profissionalização dos que estão saindo das instituições de ensino para atuar no mercado de trabalho.

Ao refletir sobre as implicações da formação para a atuação profissional, a questão-problema que motivou a realização deste estudo foi: o conhecimento produzido nos programas de pós-graduação em Administração nas universidades federais pernambucanas investiga o papel das universidades, das associações profissionais e do Estado em prol do fortalecimento da formação e atuação do Administrador?

Considerando que as universidades contribuem com a formação de futuros produtores de conhecimento (LARSON, 1979), sendo os cursos de mestrado e doutorado espaços privilegiados para o desenvolvimento de pesquisas, neste trabalho teve-se como objetivo identificar produções acadêmicas que analisem o papel das universidades (enquanto geradoras de conhecimento), das associações profissionais e do Estado em prol do fortalecimento da formação e atuação do Administrador.

Nesse âmbito, recorreu-se às contribuições de Freidson (1986, 1996, 1998, 2001) como lente teórica para nortear e analisar os dados, uma vez que para esse autor, “[...] é a combinação entre o treinamento no conhecimento formal e o credenciamento que garante às profissões um acesso exclusivo às suas posições no mercado de trabalho.” (FREIDSON, 1998, p. 24).

Para tanto, este trabalho está organizado em cinco seções: essa primeira contextualiza a temática em estudo; a segunda congrega a contribuição de diferentes autores do campo da sociologia das profissões sobre o papel do conhecimento, com destaque para os estudos de Eliot Freidson; a terceira parte apresenta os procedimentos metodológicos utilizados para a realização do trabalho; a quarta seção sistematiza os achados da pesquisa; e as considerações finais compõem a quinta seção. Por fim, são apresentadas as referências bibliográficas e as referências das teses e dissertações citadas no corpus analisado.

\section{O CONHECIMENTO COMO ELEMENTO CENTRAL NAS PROFISSÕES}

As análises sociológicas das profissões foram permeadas por contribuições de diferentes autores, mas neste estudo optou-se por delimitar e sistematizar as reflexões de alguns teóricos que deram destaque ao conhecimento como fator requerido à realização e ao desenvolvimento de determinada atividade ocupacional. 
Iniciando pela perspectiva funcionalista, observa-se que “[...] a posse de conhecimentos científicos e técnicos, complexos e especializados, obtidos após uma longa formação universitária” constitui um atributo do que caracteriza determinada profissão (GONÇALVES, 2007, p. 179). Nesse sentido, destaca-se a contribuição de Parsons (1972) ao afirmar que a diferença entre o leigo e o profissional é que este possui conhecimentos específicos e competências técnicas para desenvolver determinada atividade, além de um ideal de serviço voltado para o bem coletivo.

Entretanto, a centralização na determinação de atributos que caracterizassem as profissões foi uma das críticas que os funcionalistas receberam. A ruptura com essa abordagem surge a partir dos interacionistas, cuja análise tinha como foco o processo, considerando as características subjetivas implicadas nas atividades de trabalho, bem como as relações estabelecidas com outras atividades a fim de constituir formas de realização de si. Para Hughes (1958), pesquisador que se destaca entre os interacionistas, aspectos como a carreira e o meio de socialização devem ser considerados no estudo das profissões. Esse autor ressalta que o diploma (licença para exercer determinada atividade) e o mandato (obrigação legal de assegurar especificidades de uma ocupação) são requisitos essenciais ao exercício profissional e, ao mesmo tempo, constituem as bases para a divisão social do trabalho. Sobre o mandato, este permite que os profissionais determinem quais tarefas realizar, como e onde o trabalho deve ser feito. Além da licença para exercer determinada atividade, faz-se necessário que os membros de tal ocupação possam definir coletivamente as especificidades do seu trabalho e ter esse reconhecimento legítimo perante a sociedade. Assim, tanto o diploma quanto o mandato expressam o “domínio” de conhecimentos específicos para desenvolver determinada atividade, cuja hierarquização profissional constitui processo de diferenciação e valorização social.

Assim, o domínio de determinados conhecimentos configura-se como um elemento de poder e de exclusão social, podendo desencadear o monopólio profissional. Larson (1979) desenvolveu estudos sobre mobilização coletiva de trabalhadores especializados para conseguir prestígio e restringir o espaço de atuação profissional. As disputas profissionais constituem uma forma de assegurar um projeto de mobilidade coletiva, cujo conhecimento pode se tornar uma mercadoria. Nesse contexto, a universidade configura-se como um espaço de produção de conhecimentos e o controle do acesso à formação constitui uma das formas de exclusão social e de fechamento do mercado. Ao se tornar rara determinada expertise, há valorização e poder profissional por parte daqueles que detêm tais conhecimentos. 
Ainda nessa perspectiva, Eliot Freidson tem sido identificado como membro de uma segunda geração de interacionistas, apesar de o próprio autor não concordar com essa classificação (BONELLI, 1998). Para ele, a profissão é uma forma de organização no mercado de trabalho fundamentada na autonomia técnica, no credencialismo e no monopólio de uma área de conhecimento especializado e institucionalizado, o qual sustenta essa autonomia.

Dessa forma, as profissões poderiam tornar-se abrigos, criados pelos sistemas de credenciamento para a atuação no mercado de trabalho ocupacional. Segundo Bonelli (1998), o sistema de credenciamento apontado por Freidson apoia-se no tripé universidades, associações e Estado. Nesse âmbito, ressalta-se que os acadêmicos produzem o conhecimento abstrato e formal que dá autoridade científica à profissão.

Assim, o conhecimento possibilita ao trabalhador definir e decidir como fazer e controlar seu próprio trabalho e, segundo Freidson, esse princípio ocupacional (grau de controle exercido pelos membros de uma ocupação sobre o próprio trabalho) deveria sobressair-se ao princípio administrativo, cuja fonte de autoridade de organização do trabalho pertence a gerentes que formulam, avaliam e controlam de forma administrativa o trabalho de quem o pratica. Freidson (1998) critica o princípio administrativo e antevê a predominância do princípio ocupacional cuja autoridade está imputada na expetise. O princípio ocupacional é um contraponto ao trabalho alienado, e o credencialismo traz alguma proteção contra a incompetência de quem não tem conhecimento para realizar determinada atividade. Freidson (1998 apud BONELLI, 1998, p. 26) destaca

[...] ocupação como um conceito sociológico tão importante quanto os conceitos de classe e de organização. A dimensão desse trabalho intelectual engloba o trabalho de uma forma mais geral, articulando-o com o papel do conhecimento especializado não só na esfera econômica, mas também na vida social, cultural e política.

A ênfase dada à relevância do conhecimento especializado pode ser observada quando Freidson (2001) propõe uma terceira lógica de profissionalismo. A primeira lógica seria a do "mercado”, na qual há concorrência livre e o mundo está organizado em torno do consumo. Já a segunda lógica tem como base a racionalização do trabalho por meio da burocracia legal, com regras definidas por gestores que controlam quem produz e como produz, visando à eficiência de resultados. Por fim, o autor utiliza o 
termo profissionalismo para se referir à terceira lógica, na qual os membros de ocupações controlam o seu trabalho em vez de consumidores ou gerentes.

O profissionalismo pode existir quando uma ocupação organizada ganha o poder de determinar quem está qualificado para executar um conjunto definido de tarefas, evita que outros realizem esse trabalho e controla os critérios que permitam avaliar o desempenho. Nessa terceira lógica, nem os compradores do mercado, nem os gestores de empresas burocráticas poderiam escolher trabalhadores para executar tarefas específicas ou avaliar o seu trabalho, exceto dentro dos limites especificados pela ocupação. Para Freidson (2001), a ocupação organizada cria as circunstâncias de controle respaldadas em conhecimentos específicos que garantam essa autonomia e autoridade.

É na forma como os trabalhadores utilizam o conhecimento formal e na transposição dessa abstração que o poder profissional também acontece. Para o autor, apenas o profissionalismo é verdadeiramente capaz de lidar com o conhecimento especial e esotérico, não porque é segredo, mas por ser especializado e levar tempo e esforço para ser adquirido, fatores que merecem reconhecimento e valorização profissional. Assim, as ocupações que possuírem tais conhecimentos obtêm prestígio social (FREIDSON, 2001). Entretanto, ele alerta que existe risco na independência das profissões para escolher a direção do desenvolvimento dos seus conhecimentos e de seus usos, uma vez que o trabalho profissional pode estar subordinado às necessidades imediatas do capital e do Estado.

O desenvolvimento de um corpo especializado de conhecimento formal requer um grupo de profissionais que aprende e pratica, reconhecendo uns aos outros como colegas em virtude da sua formação comum e da experiência com determinado conjunto de tarefas, técnicas, conceitos e problemas de trabalho. Nesse contexto, é imprescindível a ética individual e institucional. Freidson (2001) acrescenta que, sem limites, nada que pudesse ser chamado apropriadamente de ocupação poderia existir. Esses limites criam abrigos sociais que se reforçam mutuamente dentro dos quais um órgão formal de conhecimento pode desenvolver uma competência que precisa ser nutrida, praticada, refinada e expandida. Para o autor, o monopólio é essencial ao profissionalismo, mas pautado em lógica diferente de competição do mercado. O fechamento visa incluir apenas os que têm o domínio de um corpo definido de conhecimentos e habilidades que garantam a prestação de um serviço de qualidade para a população. Nesse contexto, em oposição à incompetência, a credencial de treinamento é fundamental ao profissionalismo. Tal credenciamento, segundo Freidson (1998), apoia-se em um tripé no qual as universidades, as associações e o Estado aliam-se para garanti-lo. 
Por outro lado, a centralidade que é dada ao conhecimento é criticada por Abbott (1988), cujos estudos apresentam uma abordagem mais sistêmica das profissões. Para esse autor, é preciso analisar a prática laboral, as relações existentes, o tipo de trabalho e os conflitos que permeiam o desenvolvimento das profissões. Sua abordagem considera um conjunto de partes interdependentes cujas alianças e conflitos constituem elementos que precisam ser analisados. Contudo, Abbott (1988) não exclui de seus estudos a relevância do conhecimento. Ele considera que este é um elemento de disputa, destacando seu papel para a inferência, ato profissional por excelência.

\footnotetext{
Segundo Abbott (1988), a delimitação de uma área de jurisdição é realizada a partir de um conjunto de conhecimentos específicos relativos a aspectos da vida humana e social. Delimitar jurisdição é disputar internamente um campo de atividade junto a outras profissões, definindo as tarefas pertinentes a cada um, ou seja, dizer o que e quem faz, e o que e quem não pode fazer. Por isso, ao abordar as profissões, o mencionado autor defende que elas devem ser pensadas num conjunto do sistema profissional e entendidas como maneiras de inclusão e exclusão. (ACIOLI LINS, 2011, p. 33, grifo nosso).
}

Apesar de considerar as reflexões de Larson (1977) e Abbott (1988), Freidson (2001) diz que seus estudos vão além do que é apresentado por esses autores a partir do momento em que ele apresenta uma terceira lógica de abordagem (profissionalismo) para compreender como o trabalho pode ser organizado e controlado. Ao mesmo tempo, o autor reconhece que o conhecimento, somente, não possibilita um poder especial.

Tendo como base o princípio ocupacional, Freidson (1998) destaca que é preciso considerar a origem do conhecimento especializado na sociedade do futuro, a maneira pela qual ele é estabelecido e como seu desenvolvimento e utilização são organizados, avaliados e controlados.

No intuito de sistematizar as contribuições teóricas de Freidson para o fortalecimento das profissões, o Quadro 1 traz uma síntese dos principais aspectos que permeiam a terceira lógica de profissionalismo: 
Quadro 1 - Conceitos-chave da abordagem teórica de Freidson

\begin{tabular}{|c|c|}
\hline Profissão & $\begin{array}{l}\text { Forma de organização no mercado de trabalho fundamentada na autonomia } \\
\text { técnica, no credencialismo e no monopólio de uma área de conhecimento espe- } \\
\text { cializado e institucionalizado, o qual sustenta essa autonomia. }\end{array}$ \\
\hline Profissionalismo & $\begin{array}{l}\text { Existe quando uma ocupação organizada ganha o poder de determinar quem está } \\
\text { qualificado para executar um conjunto definido de tarefas, evita que outros reali- } \\
\text { zem esse trabalho e controla os critérios que permitam avaliar o desempenho. }\end{array}$ \\
\hline $\begin{array}{l}\text { Elementos que com- } \\
\text { põem o tipo ideal de } \\
\text { profissionalismo }\end{array}$ & $\begin{array}{l}\text { Trabalho especializado assente em um corpo teórico, no uso discricionário do } \\
\text { conhecimento e das competências pelo profissional; jurisdição exclusiva e di- } \\
\text { visão do trabalho controladas pela profissão; posição de monopólio no mercado } \\
\text { baseada em credenciais qualificacionais criadas pela profissão; existência de } \\
\text { um programa formal de ensino, ao nível superior, produtor dessas credenciais } \\
\text { e controlado pela profissão; existência de uma ideologia que garanta o reco- } \\
\text { nhecimento social do trabalho profissional, da sua eficiência econômica e da } \\
\text { validade do conhecimento especializado (FREIDSON, } 2001 \text { apud GONÇAL- } \\
\text { VES, 2007, p. 184). }\end{array}$ \\
\hline Monopólio & $\begin{array}{l}\text { Fechamento do mercado essencial ao profissionalismo. Visa incluir apenas os } \\
\text { que têm o domínio de um corpo definido de conhecimentos e habilidades que } \\
\text { garantam a prestação de um serviço de qualidade para a população. }\end{array}$ \\
\hline $\begin{array}{l}\text { Sistema de creden- } \\
\text { ciamento }\end{array}$ & $\begin{array}{l}\text { Apoia-se no tripé universidades (geradoras de conhecimento), associações } \\
\text { (fortalecedoras dos membros da profissão, estabelece direitos e deveres dos } \\
\text { profissionais, fiscaliza e protege seus membros) e Estado (define leis, avalia as } \\
\text { instituições de ensino, cria, aumenta ou diminui vagas, etc.). }\end{array}$ \\
\hline
\end{tabular}

Fonte: adaptado de Freidson (1986, 1996, 1998, 2001).

É nesse contexto que se insere esta pesquisa, investigando à luz das reflexões de Freidson, como a produção acadêmica realizada pelos programas de pós-graduação stricto sensu em Administração de Pernambuco tem analisado os conhecimentos que compõem a formação do Administrador. A seção subsequente apresenta o caminho metodológico percorrido para a coleta e a análise dos dados da pesquisa.

\section{PROCEDIMENTOS METODOLÓGICOS}

Esta pesquisa orientou-se pela abordagem qualitativa, cuja preocupação fundamental, segundo Merriam (1998), é compreender o fenômeno em profundidade e seus possíveis impactos na realidade vivenciada. 
O delineamento da investigação teve início com a pesquisa bibliográfica, por meio da qual foi possível sistematizar as informações sobre o objeto de estudo. Segundo Triviños (1987), na pesquisa qualitativa, novas teorias podem ser incorporadas ao arcabouço teórico durante a análise dos dados para que o fenômeno seja interpretado com maior detalhamento.

Recorreu-se às contribuições de Eliot Freidson para a sociologia das profissões, especificamente à abordagem central da sua teoria do profissionalismo como uma terceira lógica para compreender as profissões a partir do princípio ocupacional, com foco no conhecimento requerido para realizar determinadas tarefas.

Para tanto, a pesquisa teve como campo empírico os cursos de pós-graduação stricto sensu em Administração de universidades pernambucanas. Atualmente, há nove programas com cursos de mestrado e doutorado reconhecidos pela Capes em 2015 no Estado (COORDENAÇÃO DE APERFEIÇOAMENTO DE PESSOAL DE NÍVEL SUPERIOR, 2015). Os cursos analisados foram escolhidos conforme os seguintes critérios: serem programas com cursos na modalidade acadêmica, em funcionamento e reconhecidos pela Capes e terem como área de concentração a formação em Administração. Do universo existente, dois programas atenderam a esses critérios: um na Universidade Federal de Pernambuco (Ufpe) - Programa de Pós-graduação em Administração (Propad) -, com cursos de mestrado e doutorado; e outro na Universidade Federal Rural de Pernambuco (Ufrpe) - Programa de Pós-graduação em Administração e Desenvolvimento Rural (Padr) -, com curso de mestrado.

Os dados para analisar a produção acadêmica dos referidos cursos foram obtidos mediante pesquisa documental. A coleta ocorreu nos próprios sites dos programas analisados (PROGRAMA DE PÓS-GRADUAÇÃO EM ADMINISTRAÇÃO, 2015; PROGRAMA DE PÓS-GRADUAÇÃO EM ADMINISTRAÇÃO E DESENVOLVIMENTO RURAL, 2015) e validados nos bancos de teses/dissertações das universidades e da Capes (BANCO DE TESES E DISSERTAÇÕES DA UFPE, 2015; TESES E DISSERTAÇÕES DA UFRPE, 2015; PLATAFORMA SUCUPIRA, 2016), uma vez que ambos disponibilizam, de forma complementar, os trabalhos defendidos pelos egressos.

O levantamento dos trabalhos foi desenvolvido utilizando-se como descritores os seguintes termos: formação, conhecimento, Administração, Administrador, Universidade, CFA-Conselho Federal de Administração e Conselho Regional de Administração (CRA). A consulta inicial consistiu na busca desses termos no título, no resumo, no assunto e nas palavras-chave. Em seguida procedeu-se à leitura das pesquisas que possuíam algum dos descritores na busca por questões relacionadas à atuação profis- 
sional na área de Administração, bem como o papel das universidades, dos conselhos e do Estado na formação do Administrador. Esse mapeamento compreendeu o período de 1997 a 2015, respectivamente, o ano em que teve início as primeiras defesas de dissertações na área até o ano em que foi realizada a busca.

O tratamento das informações coletadas foi respaldado na análise de conteúdo temática proposta por Bardin (2009). De acordo com a autora, operacionalmente essa técnica contempla três fases: a pré-análise (leitura flutuante, constituição do corpus, formulação de hipóteses/objetivos, elaboração de índices/indicadores e organização dos arquivos); a exploração do material (operação classificatória visando alcançar o núcleo de compreensão do documento mediante categorização); e o tratamento dos resultados obtidos para a interpretação (realização de inferências fundamentadas teoricamente). A partir da análise de conteúdo, os trabalhos que apresentavam os descritores da pesquisa foram organizados em tabelas, cuja catalogação possibilitou explorar as informações por programas de pós-graduação, autores, anos das defesas, categorias temáticas, objetivos e resultados das pesquisas.

Nesse âmbito, verificou-se como a produção acadêmica dos programas analisados contempla a formação do Administrador, especificamente o conhecimento requerido para a atuação profissional e o fortalecimento da profissão. Lüdke e André (1986, p. 38) definem a análise documental como um procedimento que “[...] busca identificar informações factuais nos documentos a partir de questões de interesse [...] e compreende materiais escritos que possam ser utilizados como fontes de informação.” Por meio da pesquisa documental foi possível verificar a presença de informações que pudessem estar relacionadas ao desenvolvimento do profissionalismo apresentado por Freidson.

\section{APRESENTAÇÃO E DISCUSSÃO DOS RESULTADOS}

Esta seção sistematiza os trabalhos desenvolvidos pelos egressos dos programas analisados à luz das contribuições de Eliot Freidson.

O Programa de Pós-graduação em Administração e Desenvolvimento Rural (Padr) da Universidade Federal Rural de Pernambuco (Ufrpe) teve início em 2003 com o reconhecimento do mestrado acadêmico pela Capes. O banco de dissertações disponíveis compreende o período de 2006 a 2015, conforme detalhado na Tabela 1: 


\begin{tabular}{|c|c|c|}
\hline Ano & $\begin{array}{l}\text { Dissertações } \\
\text { defendidas }\end{array}$ & $\begin{array}{l}\text { Trabalhos que analisaram questões sobre o conhecimento na } \\
\text { formação e atuação profissional na área de Administração }\end{array}$ \\
\hline 2006 & 01 & - \\
\hline 2007 & 02 & - \\
\hline 2008 & 02 & - \\
\hline 2009 & 11 & - \\
\hline 2010 & 21 & - \\
\hline 2011 & 16 & - \\
\hline 2012 & 15 & - \\
\hline 2013 & 21 & - \\
\hline 2014 & 17 & 1 dissertação \\
\hline 2015 & 11 & - \\
\hline Total & 117 & 1 dissertação \\
\hline
\end{tabular}

Os dados apresentados na Tabela 1 expressam o quantitativo de dissertações defendidas no Padr por ano, cujo levantamento revelou que apenas um trabalho (SOUZA, 2014), do total de 117 produções, analisou o bacharelado em Administração Pública a partir das políticas de interiorização do ensino superior em Pernambuco. Apesar de o trabalho não ter como objetivo analisar o conhecimento do referido curso, foi a única evidência de pesquisa preocupada em investigar a formação na área de Administração. Essa lacuna teórico-empírica de estudos que contemplem os conhecimentos sobre a formação e atuação profissional pode comprometer, quando se recorre a Freidson (2001), o profissionalismo na área analisada.

Nos trabalhos produzidos pelos egressos do Padr, constatou-se uma predominância de estudos sobre: agronegócio, políticas públicas de desenvolvimento rural e sustentável, análise de mercados no interior de Pernambuco, arranjos produtivos locais, cana-de-açúcar, estratégias de mercado e questões de gênero na agricultura.

Freidson (1998) ressalta que, além do corpo de conhecimentos, o sistema de credenciamento apoiado no tripé universidades, associações e Estado, foi possível constatar na produção acadêmica do Padr outros trabalhos (LIMA, 2009; ALUSTAL, 2011; SOUZA, 2012; VIANA, 2013; FIRMINO; 2014) contemplando aspectos como: a contribuição da interiorização do ensino superior, a produção acadêmica em ciências agrárias, a formação do agrônomo. Apesar de essas pesquisas não estarem relacionadas diretamente à área de Administração, elas destacam, principalmente, o papel das 
universidades e a geração de conhecimentos voltados ao desenvolvimento local. Não foram identificadas pesquisas sobre associações dos profissionais da área, e o papel do Estado aparece em trabalhos sobre políticas públicas agrárias, não contemplando intervenções na profissão objeto deste estudo.

No que se refere à produção acadêmica do Programa de Pós-graduação em Administração (Propad) da Ufpe, as atividades tiveram início em 1995 com o curso de mestrado e em 2000 com o curso de doutorado. O banco de dissertações e teses disponíveis compreende o período de 1997 a 2015, conforme detalhado na Tabela 2:

Tabela 2 - Produção Acadêmica do PROPAD (Dissertações: 1997-2015 e Teses: 2005-2015)

\begin{tabular}{|c|c|c|c|}
\hline Ano & $\begin{array}{c}\text { Dissertações } \\
\text { defendidas }\end{array}$ & $\begin{array}{c}\text { Teses defen- } \\
\text { didas }\end{array}$ & $\begin{array}{c}\text { Trabalhos que analisaram questões sobre o } \\
\text { conhecimento na formação e atuação profis- } \\
\text { sional na área de Administração }\end{array}$ \\
\hline 1997 & 08 & - & - \\
\hline 1998 & 09 & - & - \\
\hline 1999 & 07 & - & - \\
\hline 2000 & 11 & - & - \\
\hline 2001 & 16 & - & 1 dissertação \\
\hline 2002 & 14 & - & 2 dissertações \\
\hline 2003 & 22 & - & - \\
\hline 2004 & 28 & - & 2 dissertações \\
\hline 2005 & 29 & 03 & 3 dissertações \\
\hline 2006 & 33 & 05 & 1 dissertação \\
\hline 2007 & 28 & 03 & - \\
\hline 2008 & 27 & 02 & - \\
\hline 2009 & 51 & 05 & 2 dissertações \\
\hline 2010 & 14 & - & - \\
\hline 2011 & 32 & 05 & 3 dissertações \\
\hline 2012 & 30 & 09 & 3 dissertações \\
\hline 2013 & 36 & 06 & 4 dissertações e 1 tese \\
\hline 2014 & 23 & 20 & - \\
\hline 2015 & 12 & 14 & 2 dissertações e 1 tese \\
\hline Total & 430 & 72 & 23 dissertações e 2 teses \\
\hline
\end{tabular}

Fonte: adaptada de Banco de Teses e Dissertações da UFPE (2015), Programa de Pós-Graduação em Administração (2015) e Plataforma Sucupira (2016).

De acordo com a Tabela 2, observa-se o quantitativo de dissertações e teses defendidas no Propad por ano, bem como os trabalhos que abordaram questões rela- 
cionadas ao conhecimento na formação e/ou atuação profissional na área de Administração.

Das 430 dissertações disponíveis, 23 contemplaram discussões sobre: percepção da qualidade do Curso de Administração (DUTRA, 2001); ensino de empreendedorismo no Curso de Administração (FERREIRA, 2002); origem e institucionalização da pós-graduação stricto sensu profissional na área de gestão (MELO, 2002); pesquisa interdisciplinar na graduação em Administração (ARAÚJO, 2004); casos de sucessos de Cursos de Administração (DINIZ, 2004); relações de conhecimento entre o consultor organizacional e o cliente (MOURA, 2005); mentoria no Curso de Administração (SANTOS JÚNIOR, 2005); impacto do programa de iniciação científica na carreira do graduando em Administração (MEDEIROS, 2005); educação em empreendedorismo (CHAVES, 2006); processo de escolha da formação em Administração (BONFIM, 2009); tecnologia e cultura do Curso de Administração (SOUZA, 2009); e-mentoring no Curso a distância de graduação em Administração (TORRES, 2011); relação tutor-aluno no curso a distância de pós-graduação em Administração (BARROS, 2011); método de ensino em Administração via jogo de simulação (SOUZA, 2011); competências profissionais do docente para lecionar Administração (MELO, 2012); prática de orientação em programas de pós-graduação stricto sensu em Administração (SALGUEIRO, 2012); letramento acadêmico dos estudantes de Administração (THOMPSON, 2012); avaliação da aprendizagem em Cursos de pós-graduação lato sensu a distância em Administração (MARTINS, 2013); teste científico de teorias da consultoria organizacional (ARRUDA, 2013); competências e comprometimento docente e discente no Curso de Administração Pública on-line (FIRMO, 2013); construção de significados da profissão de Administrador (SILVA, 2013); idiossincrasias no ensino presencial e on-line do Curso de Administração (PEREIRA, 2015); e ensino de comunicação na formação do Administrador (FEITOSA, 2015).

No que se refere às teses defendidas no Propad no período de 2005 a 2015, foram localizados 72 trabalhos, dos quais dois discutiram elementos da formação e atuação na área de Administração, a saber: ressignificação do construto mentoria na pós-graduação lato sensu a distância em Administração (SOUZA, 2013); e formação de competências gerenciais para o papel de professor-gestor em instituições federais (BARBOSA, 2015).

Apesar de ser um quantitativo relevante de produções acadêmicas (25 trabalhos), percebeu-se uma concentração em determinadas temáticas da formação e poucos estudos sobre atuação e reconhecimento da profissão de Administrador. As dissertações e teses defendidas no Propad que abordaram o conhecimento sobre Ad- 
ministração representam menos de 5\% da produção total, cuja maioria dos estudos prioriza discussões sobre: estratégias, operações e sustentabilidade; finanças corporativas; gestão de marketing, consumo e serviços e tecnologia da informação; organizações do terceiro setor; capital social; trabalho e gestão do conhecimento (em outras áreas); internacionalização; cultura criativa e organizacional; inovação, entre outros.

Também foi possível encontrar estudos sobre a atuação do professor que leciona nos cursos presenciais e a distância, tanto na graduação quanto na pós-graduação (RÉGIS, 2000; GUEIROS, 2005; SANTOS JÚNIOR, 2005; BARROS, 2011; TORRES, 2011; MELO, 2012; FIRMO, 2013; BARBOSA, 2015).

A presença de trabalhos no Propad sobre o conhecimento na área de Administração e outras produções abordando os temas de mentoria, aprendizagem, ensino e consultoria justifica-se pela existência de uma linha de pesquisa denominada Construção do conhecimento e da ação. A importância dessa linha, considerando a teoria do profissionalismo de Freidson (2001), constitui exemplo de um indicador relevante para o desenvolvimento da formação e atuação profissional na área de Administração.

Por outro lado, a maioria dos temas é abordada enaltecendo os conhecimentos empíricos em detrimento dos teóricos. Para Cunha (2008, p. 20), “[...] teoria e prática, articuladas entre si, sustentam os alicerces da formação.” Ao mesmo tempo, Freire (1996, p. 23) adverte que "[...] a reflexão crítica sobre a prática se torna uma exigência da relação Teoria/Prática sem a qual a teoria pode ir virando 'blábláblá' e a prática, ativismo.” Para eles, os saberes que emergem na vivência cotidiana profissional precisam ser refletidos de forma fundamentada. Nesse sentido, pode-se associar a experiência profissional adquirida ao que Freidson (1996) denomina "treinamento pelo ofício”. Para o autor, os saberes advindos desse meio de aprendizagem sujeitam-se à lógica de mercado e das organizações, contemplando, em sua maioria, atividades rotineiras desprovidas de reflexão crítica. Em oposição, ele defende o "treinamento profissional” que ocorre em salas de aulas de instituições de ensino, nas quais o conteúdo e o escopo da formação são abrangentes e sistemáticos, podendo compreender considerável material discursivo, inclusive conceitos e teorias abstratas que podem suscitar inferências, reflexões e transposições para diferentes situações.

Assim, para Freidson (1996), o trabalho das profissões se distingue do trabalho dos ofícios por ser uma especialização criteriosa teoricamente fundamentada. Larrosa (2002, p. 19) também destaca que o saber da experiência ocorre na mediação entre o conhecimento teórico e a prática na vida humana. Tendo como base os referidos autores, percebe-se a importância da ampliação de pesquisas tanto no Padr 
quanto no Propad, considerando a relação teoria e prática no exercício da profissão do Administrador.

Quanto aos três elementos (universidades, associações e Estado) que compõem o sistema de credenciamento apresentado por Freidson (1998), constatou-se na produção acadêmica do Propad quatro trabalhos que analisaram o papel das universidades (SILVA, 2005; ALBUQUERQUE, 2005; SANTIAGO, 2007; LINS, 2012).

Por outro lado, não foram encontradas pesquisas, tanto no Padr como no Propad, sobre a atuação dos Conselhos Estadual e Federal em Administração, bem como sobre a intervenção do Estado na profissão. O Conselho Federal de Administração (CFA) é um órgão normativo, consultivo, orientador e disciplinador do exercício da profissão, sendo uma de suas principais atividades fiscalizar o exercício da profissão, determinando, inclusive, atividades privativas que somente deveriam ser desenvolvidas por bacharéis em Administração. Essas estratégias de fechamento e monopólio profissional, defendidas por Freidson (1998, 2001), não são efetivas na área analisada, uma vez que há profissionais de outras áreas exercendo atividades administrativas. Assim, existe uma pseudoideia (RIBEIRO, 2015) de que “[...] qualquer um possa atuar como Administrador.”

Foi nesse sentido que a intervenção do Estado veio a prejudicar o profissionalismo dessa área quando um político apresentou o Projeto de Lei n. 7.280/2010 (CÂMARA DOS DEPUTADOS, 2012). A Ementa do referido projeto objetivava modificar a regulamentação da profissão de Administrador (Lei n. 4.769, de 09 de setembro de 1965), permitindo que profissionais de outras áreas, mas com mestrado e doutorado em Administração, exercessem a profissão. Essa tentativa de intervenção do Estado foi indeferida e arquivada a partir de uma mobilização dos bacharéis em Administração e de seus conselhos (CONSELHO FEDERAL DE ADMINISTRAÇÃO, 2010) em defesa da atuação preservada para o profissional que tivesse a graduação na referida área.

Interessante observar que esse contexto permeia os conflitos existentes na atuação e na definição do corpo de conhecimentos que deve compor a formação dos bacharéis em Administração, por meio de pesquisas realizadas pelo Conselho Federal de Administração (2015b). Entretanto, tais aspectos não apareceram na produção acadêmica do Padr, nem do Propad até 2015. É pertinente destacar que nenhuma pesquisa realizada nos respectivos programas analisou a produção acadêmica de seus cursos de mestrado e doutorado. Também não foi localizado nenhum estudo analisando as diferenças existentes dentro do grupo de profissionais que atuam na área de Administração. As variações existem e estão diretamente relacionadas ao salário, podendo 
contemplar também alguns benefícios e formas diferenciadas de tratamento para Administradores que exercem o mesmo cargo, porém, em áreas diferentes. Tendo como base o Guia de Profissões e Salários da Catho, Veronezzi (2015) destaca que a média salarial de um Administrador que ocupa um cargo de analista de logística e suprimentos é de $\mathrm{R} \$ 2.484,00$, enquanto um profissional com a mesma formação ocupando o cargo de analista econômico-financeiro ganha em média R\$ 4.079,00.

Para Freidson (1998), a variação nos arranjos de emprego é mais importante do que o simples fato de se estar empregado. O modelo de profissionalismo do autor também considera as diferenças existentes no mesmo grupo de profissionais. A diferenciação e valorização de determinada área de conhecimento na mesma profissão, quando os profissionais ocupam o mesmo cargo, podem gerar desmotivação pessoal e, em nível macro, hierarquização social. Freidson (2001) também adverte sobre as implicações dessas questões no desenvolvimento e controle de novos conhecimentos e habilidades e na estratificação dentro de ocupações. Para o autor, tais fatores podem influenciar as instituições de ensino a privilegiarem determinada área em detrimento de outra, podendo comprometer o profissionalismo. Tais divergências poderiam ser investigadas, de forma crítica, nas pesquisas realizadas nos cursos de mestrado e doutorado em prol do fortalecimento da profissão.

Para que o profissionalismo (controle e autonomia do trabalho) se estabeleça em determinada profissão, Freidson $(1996,1998)$ ainda destaca que o conhecimento especializado aprendido nas instituições educacionais não é suficiente. Para ele, o profissionalismo como tipo ideal remete a trabalhadores que, munidos de conhecimento, possam criar e aplicar aos assuntos humanos o discurso, a disciplina ou o campo particular sobre os quais têm jurisdição. Assim, as pesquisas realizadas nas universidades poderiam abordar questões que mobilizassem as associações e o Estado para assegurarem o direito exclusivo de usar o conhecimento para a profissão adquirir poder. O conhecimento continua sendo pré-requisito, na visão do referido autor, para o desenvolvimento do profissionalismo.

Nesse contexto, a “[...] profissionalização compreende o estabelecimento da autoridade para coordenar uma divisão do trabalho baseando-se na autoridade da $e x$ pertise, que por sua vez é estabelecida por um processo social e político.” (FREIDSON, 1998, p. 101). Dessa forma, o profissional terá as condições de obter o direito exclusivo de realizar e controlar o trabalho, definindo a maneira como será desenvolvido e avaliado. Os programas de pós-graduação precisam contemplar essas discussões em suas pesquisas em prol do desenvolvimento dos profissionais que atuam na área de Administração. 


\section{CONSIDERAÇÕES FINAIS}

Este estudo teve como ponto de partida as contribuições de Freidson, o qual considera que uma profissão é uma especialização proveniente de uma expertise desenvolvida nas instituições de ensino mediante a apropriação de conhecimentos. Para o autor, “[...] o treinamento no conhecimento formal e o credenciamento garantem às profissões um acesso exclusivo às suas posições no mercado de trabalho.” (FREIDSON, 1998, p. 24). A partir desse referencial e da análise dos documentos que compuseram o corpus da pesquisa, constatou-se que a produção acadêmica dos programas de pós-graduação analisados, especialmente a do Propad, contempla estudos sobre o conhecimento construído e socializado no Curso de Administração na graduação presencial e a distância.

Freidson (2001) ressalta o papel das instituições de ensino no que ele denomina "treinamento profissional”, porém adverte que o conhecimento também pode desencadear problemas de acesso social e ser distribuído de forma desigual. Para o autor, a estratificação dentro da mesma profissão enfraquece o profissionalismo de determinada área, como pode ser observado na diferenciação salarial de uma especialização em detrimento de outras em determinados cargos exercidos pelo bacharel em Administração. Estudos que examinassem essas variações não foram identificados na produção acadêmica dos cursos analisados.

Sobre o conhecimento produzido nas universidades, Freidson (2001) alerta que é preciso refletir sobre as implicações das instituições de formação para o desenvolvimento e controle de novos conhecimentos, bem como para a estratificação dentro das ocupações. As instituições são fundamentais, porém é necessário pensar sobre os seus próprios limites e os fatores que interferem na sua produção. Na área de Administração tem-se uma forte influência do mercado sobre o perfil e os conhecimentos que devem compor a formação dos profissionais os quais atuarão nas organizações.

No que se refere ao tripé que apoia o credencialismo tratado por Freidson (1998), apenas foram encontrados trabalhos sobre o papel das universidades, o que demonstra uma lacuna de pesquisas sobre a atuação e a intervenção das associações e do Estado no exercício da profissão de Administrador. Para analisar o profissionalismo, o autor ressalta que é preciso examinar o papel e a atuação do Estado e da associação profissional, considerando as influências na profissão provenientes da ideologia e da substância de determinados campos ou disciplinas. Para ele, “[...] é pela análise da variação desses fatores que nos tornamos aptos a entender a variação efetivamente 
alcançada pelas ocupações históricas no grau de profissionalismo e no poder do seu discurso.” (FREIDSON, 1996, p. 4).

Outro aspecto que merece destaque é o poder que o Administrador exerce em sua profissão. Percebe-se que os profissionais que atuam nessa área possuem o que Freidson (1996) denomina autoridade técnica restrita, uma vez que, assim como os engenheiros, a maioria dos administradores trabalha em empresas voltadas à produção de bens e serviços lucrativos, nas quais o princípio ocupacional do profissionalismo não faz parte da cultura organizacional. Talvez essas limitações justifiquem a busca de conhecimentos desses profissionais para atuar, de forma autônoma, como consultores, em contato direto com o público para o qual prestarão seus serviços. Essa forma de atuação lhes possibilitaria definir e controlar seu próprio trabalho, conforme defendido por Freidson. Trata-se de uma alternativa de atuação profissional, que requer conhecimentos especializados, cuja preocupação tem se tornado tema de pesquisas conforme identificado na produção acadêmica do Propad, a exemplo de Moura (2005) e Arruda (2013).

Reitera-se que os critérios apresentados por Freidson (1998) como essenciais ao profissionalismo, principalmente o conhecimento especializado adquirido nas instituições de ensino, podem, na visão do próprio autor, constituir elemento de inclusão e exclusão, mas também de hierarquização e diferenciação profissional. Refletir sobre a atuação do Administrador, à luz das contribuições sociológicas de Freidson para o estudo das profissões, possibilitou analisar o corpo de conhecimentos contemplados na formação das instituições analisadas e os elementos que são essenciais ao sistema de credenciamento.

Contudo, trata-se de um limitado levantamento de produções acadêmicas por se restringir a dois programas de pós-graduação. Diante disso, como estudos posteriores, sugere-se realizar o mapeamento na base de dados da Capes, bem como desenvolver pesquisas relacionadas à atuação do Estado e das associações, especificamente dos Conselhos Estadual e Federal em Administração. Tais proposições têm o objetivo de ampliar o debate sobre o direito exclusivo de usar o conhecimento específico da área, a fim de que o Administrador possa obter maior fortalecimento da classe profissional e reconhecimento social. 


\section{REFERÊNCIAS}

ABBOTT, A. The System of Professions: an essay on the division of expert labor. Chicago: Chicago University Press, 1988.

ACIOLI LINS, C. P. Professor não dá aula, professor desenvolve aula: mudanças nas atividades docentes e o processo de profissionalização do professor - o caso do professor de Ensino Médio. 2011. 297 p. Tese (Doutorado em Sociologia)-Universidade Federal de Pernambuco, Recife, 2011.

ALBUQUERQUE, S. B. de. Sistema de inovação baseado em conhecimento e o modelo tríplice hélice: a universidade na construção da vantagem competitiva do setor de tecnologia da informação de Pernambuco. 2005. 150 p. Dissertação (Mestrado em Administração)- Universidade Federal de Pernambuco, Recife, 2005.

ALUSTAL, L. T. de. Cultura e educação como fatores de desenvolvimento local: o papel da educação na preservação da identidade cultural no município de Bezerros - PE. 2011. 147 p. Dissertação (Mestrado em Administração e Desenvolvimento Rural)-Universidade Federal Rural de Pernambuco, Recife, 2011.

ARAÚJO, F. R. de S. A pesquisa interdisciplinar na graduação em Administração: um estudo sobre condições para sua prática nas IES de Pernambuco. 2004. 95 p. Dissertação (Mestrado Administração)-Universidade Federal de Pernambuco, Recife, 2004.

ARRUDA, J. L. M. Um teste científico de teorias da consultoria organizacional: a experiência do SESI com a aprendizagem gerencial. 2013. 304 p. Dissertação (Mestrado em Administração)-Universidade Federal de Pernambuco, Recife, 2013.

BANCO DE TESES E DISSERTAÇÕES DA UFPE. Produção Acadêmica do Programa de Pós-graduação em Administração. Disponível em: <http://goo.gl/ gZrbqF>. Acesso em: 28 dez. 2015.

BARBOSA, M. A. C. A influência das políticas públicas e políticas organizacionais para a formação de competências gerenciais no papel de professor-gestor no ensino superior: um Estudo em uma IES Federal. 2015. 227 p. Tese (Doutorado em Administração)-Universidade Federal de Pernambuco, Recife, 2015.

BARDIN, L. Análise de Conteúdo. Lisboa: Edições 70, 2009. 
BARROS, H. A. Relação tutor-aluno: um estudo sobre o e-mentoring e aspectos de gerenciamento de impressões em pós-graduação de Administração na educação à distância. 2011. 130 p. Dissertação (Mestrado em Administração)-Universidade Federal de Pernambuco, Recife, 2011.

BONELLI, M. da G. Contribuições sociológicas de Eliot Freidson. In: FREIDSON, Eliot. Renascimento do Profissionalismo. São Paulo: Edusp, 1998.

BONFIM, R. F. da C. A decisão da formação em Administração: um estudo sobre o processo de escolha de IES por alunos concluintes do ensino médio em Manaus. 2009. 142 p. Dissertação (Mestrado em Administração)-Universidade Federal de Pernambuco, Recife, 2009.

CÂMARA DOS DEPUTADOS. Projeto de Lei - PL 7.280/2010. Acrescenta alíneas “d”, “e” e “f” ao art. $3^{\circ}$ da Lei no 4.769, de 9 de setembro de 1965, que regulamenta o exercício da profissão de Administração para permitir aos diplomados em cursos superiores de Tecnologia, Mestrados e Doutorados em Administração o exercício da profissão. Indeferido e Arquivado. 05 mar. 2012. Disponível em: <http:// goo.gl/Ygnjm5>. Acesso em: 18 dez. 2015.

CHAVES, H. de Q. Educação em empreendedorismo: a potencialização de negócios por meio do desenvolvimento de competências do empreendedor. 2006. 183 p. Dissertação (Mestrado em Administração)-Universidade Federal de Pernambuco, Recife, 2006.

CONSELHO FEDERAL DE ADMINISTRAÇÃO. História da Profissão. Disponível em: <http://goo.gl/lwO5dF>. Acesso em: 28 dez. 2015a.

CONSELHO FEDERAL DE ADMINISTRAÇÃO. Ofício n. 1572/2010/CFA/GAB -Assunto PL 7280/10. 2010. Disponível em: <http://goo.gl/r1c87>. Acesso em: 28 dez. 2015.

CONSELHO FEDERAL DE ADMINISTRAÇÃO. Pesquisa - Perfil, formação, atuação e oportunidade de trabalho. Disponível em: <http://goo.gl/KzVbyC>. Acesso em: 28 dez. 2015b.

COORDENAÇÃO DE APERFEIÇOAMENTO DE PESSOAL DE NÍVEL SUPERIOR. Cursos recomendados e reconhecidos até 20.03.2015. Disponível em: <http://goo.gl/nJNjiv>. Acesso em: 30 nov. 2015. 
CUNHA, M. I. da. Inovações pedagógicas: o desafio da reconfiguração de saberes na docência universitária. São Paulo: USP, 2008. (Cadernos Pedagogia Universitária).

CUNHA, M. I. da. O lugar da formação do professor universitário: o espaço da pós-graduação em Educação em questão. Revista Diálogo Educacional, Curitiba, v. 9, n. 26, p. 81-90, jan./abr. 2009.

DINIZ, G. S. Vantagem competitiva em faculdades particulares: análise de três casos de sucesso em cursos de Administração. 2004. 144 p. Dissertação (Mestrado em Administração)-Universidade Federal de Pernambuco, Recife, 2004.

DUTRA, H. F. de O. Percepção de qualidade no serviço educacional: um estudo sobre o curso de Administração da Faculdade de Ciências Humanas - ESUDA. 2001. 196 p. Dissertação (Mestrado em Administração)-Universidade Federal de Pernambuco, Recife, 2001.

FEITOSA, R. A. V. de A. R. Importa ao Administrador Comunicar-se? O Ensino da Comunicação na Formação do Administrador em IES do Grande Recife/PE. 2015. 182 p. Dissertação (Mestrado em Administração)-Universidade Federal de Pernambuco, Recife, 2015.

FERREIRA, P. G. G. Incentivo e inibição ao empreendedorismo pelas práticas didático-pedagógicas dos cursos de graduação em Administração da região metropolitana do Recife segundo os alunos empreendedores. 2002. 94 p. Dissertação (Mestrado em Administração)-Universidade Federal de Pernambuco, Recife, 2002.

FIRMINO, A. L. da S. A interiorização das universidades federais e os arranjos produtivos locais: o caso da Unidade Acadêmica de Garanhuns (UAG/UFRPE). 2014. 121 p. Dissertação (Mestrado em Administração e Desenvolvimento Rural)Universidade Federal Rural de Pernambuco, Recife, 2014.

FIRMO, L. A. Competências dos professores e comprometimento docente e discente na EAD on-line: o caso do curso de Administração Pública da Universidade de Pernambuco. 2013. 161 p. Dissertação (Mestrado em Administração)-Universidade Federal de Pernambuco, Recife, 2013.

FREIDSON, E. Para uma análise comparada das profissões: a institucionalização do discurso e do conhecimento formais. Revista Brasileira de Ciências Sociais, v. 11, n. 31, p. 1-11, 1996. 
FREIDSON, E. Professionalism: the trird logic. Chicago: Chicago University Press, 2001.

FREIDSON, E. Professional Powers: a study of institutionalization of formal knowledge. Chicago, Londres: The University of Chicago Press, 1986.

FREIDSON, E. Renascimento do Profissionalismo: teoria, profecia e política. Tradução Celso Mauro Paciornik. São Paulo: Edusp, 1998. (Clássicos 12).

FREIRE, P. Pedagogia da Autonomia: saberes necessários à prática educativa. São Paulo: Paz e Terra, 1996.

GONÇALVES, C. M. Análise sociológica das profissões: principais eixos de desenvolvimento. Sociologia, Revista da Faculdade de Letras da Universidade do Porto, v. 17, p. 177-224, 2007.

GUEIROS, M. G. Estresse ocupacional de professores: seus indicadores, suas fontes e as estratégias utilizadas para combatê-lo - um estudo de caso na Universidade Federal de Pernambuco. 2005. 126 p. Dissertação (Mestrado em Administração)Universidade Federal de Pernambuco, Recife, 2005.

HUGHES, E. C. The men and their work. New York: Free Press, 1958.

INSTITUTO NACIONAL DE ESTUDOS E PESQUISAS EDUCACIONAIS ANÍSIO TEIXEIRA. Censo da Educação Superior - 2013 e 2014. Disponível em: <http://goo.gl/szYXB1>. Acesso em: 02 jan. 2015.

LARROSA, J. B. Notas sobre a experiência e o saber de experiência. Revista Brasileira de Educação, n. 19, p. 20-28, 2002.

LARSON, M. S. The rise of professionalism: a sociological analysis. Berkeley: University of California Press, 1979.

LIMA, V. H. D’A. O conhecimento tradicional e os saberes locais em comunidades costeiras: um estudo de caso da Ilha de Deus em Recife. 2009. 126 p. Dissertação (Mestrado em Administração e Desenvolvimento Rural)-Universidade Federal Rural de Pernambuco, Recife, 2009. 
LINS, S. A. G. Inovação social e seu processo de institucionalização no contexto de uma universidade pública: o caso do Núcleo de Saúde Pública e Desenvolvimento Social da Universidade Federal de Pernambuco (NUSP/UFPE). 2012. 133 p. Tese (Doutorado em Administração)-Universidade Federal de Pernambuco, Recife, 2012.

LÜDKE, M.; ANDRÉ, M. E. D. A. Pesquisa em Educação: abordagens qualitativas. São Paulo: EPU, 1986.

MARTINS, M. A. B. Avaliação da aprendizagem em cursos de pós-graduação lato sensu em Administração EAD on-line: um estudo em uma instituição de ensino superior privada sob a ótica da Taxonomia de Bloom Digital. 2013. 184 p. Dissertação (Mestrado em Administração)-Universidade Federal de Pernambuco, Recife, 2013.

MEDEIROS, R. A. S. de M. O impacto do programa de iniciação científica (CNPq) na carreira do graduando, à luz dos fenômenos de mentoria e de competência: o caso dos alunos do curso de Administração da UFPE. 2005. 207 p. Dissertação (Mestrado em Administração)-Universidade Federal de Pernambuco, Recife, 2005.

MELO, K. V. A. Origem e institucionalização da pós-graduação stricto sensu profissional: um estudo de casos. 2002. 242 p. Dissertação (Mestrado em Administração)- Universidade Federal de Pernambuco, Recife, 2002.

MELO, R. de C. B. de. Competências profissionais do professor do ensino superior para lecionar Administração, pós-graduação lato sensu, na EAD on-line: um estudo em IES na Região Metropolitana do Recife. 2012. 179 p. Dissertação (Mestrado em Administração)- Universidade Federal de Pernambuco, Recife, 2012.

MERRIAM, S. Qualitative research and case study applications in education. San Francisco: Jossey-Bass, 1998.

MOURA, G. L. Relações de conhecimento consultor organizacional-cliente à luz da Biologia do Conhecer: uma reinterpretação para desfazer mal-entendidos correntes. 2005. 132 p. Dissertação (Mestrado em Administração)-Universidade Federal de Pernambuco, Recife, 2005.

PARSONS, T. Professions. In: SHILLS, D. International Encyclopedia of the Social Sciences. New York: MacMillan, 1972. p. 536-546. 
PEREIRA, M. R. Jeitinho Brasileiro: Idiossincrasias no ensino presencial e na EAD on-line dos cursos de Administração e de Ciências Contábeis. 2015. Dissertação (Mestrado em Administração)-Universidade Federal de Pernambuco, Recife, 2015.

PIMENTA, S. G. (Org.). Saberes Pedagógicos e Atividade Docente. São Paulo: Cortez, 2002.

PLATAFORMA SUCUPIRA. Trabalhos de Conclusão. Disponível em: < https:// goo.gl/buh0Ml>. Acesso em: 04 jan. 2016.

PROGRAMA DE PÓS-GRADUAÇÃO EM ADMINISTRAÇÃO. Dissertações Defendidas (1997-2015). Disponível em: <https://goo.gl/eGQ1dK>. Acesso em: 28 dez. 2015a.

PROGRAMA DE PÓS-GRADUAÇÃO EM ADMINISTRAÇÃO E DESENVOLVIMENTO RURAL. Dissertações Defendidas (2006-2015). Disponível em: <http:// goo.gl/isrgBt>. Acesso em: 27 dez. 2015.

PROGRAMA DE PÓS-GRADUAÇÃO EM ADMINISTRAÇÃO. Teses Defendidas (2005-2015). Disponível em: <https://goo.gl/eae47T>. Acesso em: 28 dez. $2015 b$.

RÉGIS, H. P. Um exame da motivação dos professores para participarem de um programa da qualidade no CEFET-PB com base na teoria da expectância. 2000. 219 p. Dissertação (Mestrado em Administração)-Universidade Federal de Pernambuco, Recife, 2000.

RIBEIRO, S. D. Qualquer um pode ser Administrador? 2015. Disponível em: <http://goo.gl/4rw4Pz>. Acesso em: 20 dez. 2015.

\section{SALGUEIRO, J. C. F. A prática de orientação em programas de pós-graduação} strictu sensu, à luz dos fundamentos e princípios da mentoria: a experiência de orientadores e orientados do programa de pós-graduação da UFPE. 2012. 163 p. Dissertação (Mestrado em Administração)-Universidade Federal de Pernambuco, Recife, 2012.

SANTIAGO, L. de M. K. C. Universidades Corporativas: incorporação de elementos da organização aos processos de aprendizagem organizacional. 2007. 141 p. Dissertação (Mestrado em Administração)-Universidade Federal de Pernambuco, Recife, 2007. 
SANTOS JÚNIOR, L. S. dos. O fenômeno da mentoria na percepção dos professores do curso de Administração da Faculdade Integrada do Recife. 2005. 139 p. Dissertação (Mestrado em Administração)-Universidade Federal de Pernambuco, Recife, 2005.

SILVA, S. M. G. Sobre a interferência da produção científica e tecnológica da universidade no desenvolvimento local: o caso da Ciência da Computação. 2005. 352 p. Tese (Doutorado em Administração)-Universidade Federal de Pernambuco, Recife, 2005.

SILVA, T. D. L. da. Que profissão é essa? A Construção de significados para a profissão do Administrador em sites acessados por futuros graduandos. 2013. 141 p. Dissertação (Mestrado em Administração)-Universidade Federal de Pernambuco, Recife, 2013.

SOUZA, D. C. de. Ressignificação do construto mentoria na pós-graduação lato sensu a distância em Administração. 2013. 216 p. Tese (Doutorado em Administração)- Universidade Federal de Pernambuco, Recife, 2013.

SOUZA, E. R. de. Políticas públicas e formação de capital humano: um enfoque sobre a interiorização do bacharelado em Administração Pública em Pernambuco. 2014. 86 p. Dissertação (Mestrado em Administração e Desenvolvimento Rural)Universidade Federal Rural de Pernambuco, Recife, 2014.

SOUZA, J. R. de. Análise do impacto e dos condicionantes de um método de ensino em Administração via jogo de simulação. 2011. 156 p. Dissertação (Mestrado em Administração)-Universidade Federal de Pernambuco, Recife, 2011.

SOUZA, R.-J. H. de. Impacto da tecnologia da informação na cultura organizacional do Curso de Administração do Centro Universitário no Norte - UNINORTE. 2009. 122 p. Dissertação (Mestrado em Administração)-Universidade Federal de Pernambuco, Recife, 2009.

SOUZA, V. L. P. de. A contribuição do estágio curricular supervisionado na formação profissional do graduando em agronomia da UFRPE. 2012. 97 p. Dissertação (Mestrado em Administração e Desenvolvimento Rural)-Universidade Federal Rural de Pernambuco, Recife, 2012.

TESES E DISSERTAÇÕES DA UFRPE. Produção Acadêmica do Programa de Pós-Graduação em Administração e Desenvolvimento Rural. Disponível em: <http://goo.gl/ N5A0ts>. Acesso em: 27 dez. 2015. 
THOMPSON, A. C. R. T. da F. Práticas de leitura e de produção textual do gênero resenha como eventos de letramento acadêmico: o caso de estudantes de Administração de uma universidade pública de Recife. 2012. 165 p. Dissertação (Mestrado em Administração)- Universidade Federal de Pernambuco, Recife, 2012.

TORRES, M. A. P. de O. A relação de e-mentoring entre professores (titular e tutor) e alunos na educação a distância: um estudo de caso no curso de graduação em Administração da UEPB. 2011. 104 p. Dissertação (Mestrado em Administração)- Universidade Federal de Pernambuco, Recife, 2011.

TRIVIÑOS, A. N. S. Introdução à pesquisa em ciências sociais: a pesquisa qualitativa em educação. São Paulo: Atlas, 1987.

VERONEZZI, F. Quanto ganha um Administrador? Disponível em: <http://goo. gl/DdDIlp>. Acesso em: 20 dez. 2015.

VIANA, M. da P. da S. A contribuição das pesquisas em Ciências Agrárias da Universidade Federal Rural de Pernambuco para o aumento do rendimento da cana-de-açúcar em Pernambuco: o caso da estação experimental de cana-de-açúcar de Carpina. 2013. 64 p. Dissertação (Mestrado em Administração e Desenvolvimento Rural)-Universidade Federal Rural de Pernambuco, Recife, 2013.

WEBER, S. Profissionalização docente e políticas públicas no Brasil. Educação e Sociedade, Campinas, v. 24, n. 85, p. 1125-1154, 2003.

\section{Como citar este artigo:}

\section{ABNT}

SILVA, Fabiana Ferreira. O conhecimento produzido pelos programas de pós-graduação em Administração nas universidades pernambucanas: análise da produção acadêmica à luz do profissionalismo de Eliot Freidson. RACE, Revista de Administração, Contabilidade e Economia, Joaçaba: Ed. Unoesc, v. 16, n. 1, p. 147-174,, jan./abr. 2017. Disponível em: <http://editora.unoesc.edu.br/index.php/race>. Acesso em: dia/mês/ano.

APA

Silva, F. F. (2017). O conhecimento produzido pelos programas de pós-graduação em Administração nas universidades pernambucanas: análise da produção acadêmica à luz do profissionalismo de Eliot Freidson. RACE, Revista de Administração, Contabilidade e Economia, 16(1), 147-174. Recuperado em dia/mês/ano, de http:// editora.unoesc.edu.br/index.php/race 
